\title{
FIXED POINT THEOREMS FOR NONEXPANSIVE MAPPINGS ON NONCONVEX SETS IN UCED BANACH SPACES
}

\author{
WEI-SHIH DU, YOUNG-YE HUANG, and CHI-LIN YEN
}

Received 25 July 2001 and in revised form 10 January 2002

\begin{abstract}
It is shown that every asymptotically regular or $\lambda$-firmly nonexpansive mapping $T: C \rightarrow C$ has a fixed point whenever $C$ is a finite union of nonempty weakly compact convex subsets of a Banach space $X$ which is uniformly convex in every direction. Furthermore, if $\left\{T_{i}\right\}_{i \in I}$ is any compatible family of strongly nonexpansive self-mappings on such a $C$ and the graphs of $T_{i}, i \in I$, have a nonempty intersection, then $T_{i}, i \in I$, have a common fixed point in $C$.
\end{abstract}

2000 Mathematics Subject Classification: 47H09, 47H10.

1. Introduction. The closed unit ball and the unit sphere of a real Banach space $(X,\|\cdot\|)$ are denoted by $B(X)=\{x \in X:\|x\| \leq 1\}$ and $S(X)=\{x \in X:\|x\|=1\}$, respectively. The function $\delta_{X}:[0,2] \rightarrow[0,1]$, defined by $\delta_{X}(\varepsilon)=\inf \{1-\|(x+y) / 2\|$ : $x, y \in B(X),\|x-y\| \geq \varepsilon\}$ for any $\varepsilon \in[0,2]$, is called the modulus of convexity of the Banach space $X$. The Banach space $X$ is called uniformly convex (UC) if $\delta_{X}(\varepsilon)>0$ for every $\varepsilon>0$. When $\delta_{X}(2)=1$, the space $X$ is said to be strictly convex, that is, $\|(x+y) / 2\|<1$ whenever $x, y \in B(X)$ satisfy $\|x-y\|>0$. For each $\varepsilon>0$, the modulus of convexity of $X$ in the direction $z \in S(X)$ is defined by $\delta(\varepsilon, z)=\inf \{1-\|(x+y) / 2\|$ : $x, y \in B(X), x-y=\lambda z,|\lambda| \geq \varepsilon\}$. Obviously, $\delta_{X}(\varepsilon)=\inf \{\delta(\varepsilon, z): z \in S(X)\}$. A Banach space $X$ is called uniformly convex in every direction (UCED) if for any $z \in S(X)$ and $\varepsilon>0, \delta(\varepsilon, z)>0$. It is clear that every UC Banach space is UCED and every UCED Banach space is strictly convex.

Let $C$ be a nonempty closed subset of a Banach space $X$. A mapping $T: C \rightarrow C$ is said to be nonexpansive if $\|T x-T y\| \leq\|x-y\|$ for all $x, y \in C$. A nonexpansive mapping $T$ on $C$ is said to be asymptotically regular on $C$ if $\lim _{n \rightarrow \infty}\left\|T^{n} x-T^{n+1} x\right\|=$ 0 for any $x$ in $C$. A nonexpansive mapping $T: C \rightarrow C$ is strongly nonexpansive if whenever $\left\{x_{n}-y_{n}\right\}_{n=1}^{\infty}$ is bounded and $\left\|x_{n}-y_{n}\right\|-\left\|T x_{n}-T y_{n}\right\| \rightarrow 0$ it follows that $\left(x_{n}-y_{n}\right)-\left(T x_{n}-T y_{n}\right) \rightarrow 0$, as $n \rightarrow \infty$. If there exists a $\lambda \in(0,1)$ such that $\| T x-$ $T y\|\leq\|(1-\lambda)(x-y)+\lambda(T x-T y) \|$ for all $x, y$ in $C$, then $T$ is said to be $\lambda$-firmly nonexpansive. For details of these mappings, see $[1,3]$. It is obvious that every $\lambda$ firmly nonexpansive mapping is nonexpansive. In view of [3, Proposition 1.2], we see that every strongly nonexpansive mapping $T: C \rightarrow C$ on a nonempty weakly compact convex subset $C$ of a Banach space $X$ is asymptotically regular.

In general, for a nonexpansive self-mapping $T$ on $C$, the fixed point set $F(T)=\{x \in$ $C: T x=x\}$ may be empty. The basic theorem about the existence of fixed points for a nonexpansive mapping $T$ is independently due to Browder [2], Göhde [5], and Kirk [8]. 
From the point of view of fixed point theorem for the class of closed convex subset $C$, $\lambda$-firmly nonexpansive mappings $T: C \rightarrow C$ do not exhibit better behavior than nonexpansive mappings (cf. [4, page 43]). However, the story is completely different if $C$ is nonconvex. For details, see Smarzewski [9], whose work was extended by Hong and Huang [6] to a weakly commutative family of $\lambda$-firmly nonexpansive mappings instead of a single mapping. In this paper, we show that the Smarzewski fixed point theorem for $\lambda$-firmly nonexpansive mappings remains true when the underlying space is a UCED Banach space. Further, the fixed point problem for asymptotically regular or strongly nonexpansive self-mappings on a nonconvex subset of a UCED Banach space is also investigated. It is shown that every asymptotically regular nonexpansive mapping $T: C \rightarrow C$ has a fixed point whenever $C$ is a finite union of nonempty weakly compact convex subsets $C_{k}$ of a UCED Banach space. Moreover, if $\left\{T_{i}\right\}_{i \in I}$ is any compatible family of strongly nonexpansive self-mappings on such a $C$ and the graphs of $T_{i}, i \in I$, have nonempty intersection, then $T_{i}, i \in I$, have a common fixed point in $C$.

2. Fixed point theorems for asymptotically regular or $\lambda$-firmly nonexpansive mappings. Let $C$ be a nonempty subset of a Banach space $X$ and $\left\{x_{j}\right\}$ a bounded sequence in $X$. The asymptotic radius of $\left\{x_{j}\right\}$ at a point $x \in X$ is the number $\overline{\lim }_{j \rightarrow \infty} \| x-$ $x_{j} \|$ and is denoted by $r\left(x,\left\{x_{j}\right\}\right)$. The number $r\left(C,\left\{x_{j}\right\}\right)$, defined by $\inf \left\{r\left(x,\left\{x_{j}\right\}\right)\right.$ : $x \in C\}$, is called the asymptotic radius of $\left\{x_{j}\right\}$ with respect to $C$. A point $z$ in $C$ is said to be an asymptotic center of $\left\{x_{j}\right\}$ with respect to $C$ if $r\left(z,\left\{x_{j}\right\}\right)=r\left(C,\left\{x_{j}\right\}\right)$. The set of all asymptotic centers is denoted by $A\left(C,\left\{x_{j}\right\}\right)$.

In this section, we show that every bounded sequence $\left\{x_{j}\right\}$ in a UCED Banach space $X$ has a unique asymptotic center with respect to any nonempty weakly compact convex subset $C$ of $X$, and then apply this result to study the fixed point property for asymptotic regular or $\lambda$-firmly nonexpansive mappings.

LEMMA 2.1. Let $C$ be any nonempty weakly compact convex subset of a Banach space $X$. Then for any bounded sequence $\left\{x_{j}\right\}$ in $X, A\left(C,\left\{x_{j}\right\}\right)$ is nonempty.

Proof. This follows from the observation that $f: C \rightarrow[0, \infty)$ defined by $f(x)=$ $r\left(x,\left\{x_{j}\right\}\right)$ for $x \in C$ is norm continuous and convex, therefore, weakly lower semicontinuous, and so attains its minimum on the weakly compact set $C$.

LEMMA 2.2. Every bounded sequence in a UCED Banach space X has a unique asymptotic center with respect to any nonempty weakly compact convex subset of $X$.

Proof. Let $\left\{x_{j}\right\}$ be any bounded sequence in $X$ and $C$ a nonempty weakly compact convex subset of $X$. Put $f(x)=r\left(x,\left\{x_{j}\right\}\right)$ for $x \in X$ and denote $r\left(C,\left\{x_{j}\right\}\right)$ by $m$. By Lemma 2.1, it suffices to show that $A\left(C,\left\{x_{j}\right\}\right)$ consists of exactly one point. Assume that there were two distinct points $u$ and $v$ in $A\left(C,\left\{x_{j}\right\}\right)$. Then $m>0$ and $u-v=\lambda z$ for some $\lambda>0$ and $z \in S(X)$. Since $X$ is UCED, for the above $z$ and $\varepsilon:=(m+1)^{-1} \lambda>0$, we have $\delta(\varepsilon, z)>0$. Choose $\eta \in(0,1)$ so that $(m+\eta)(1-\delta(\varepsilon, z))<m$. Then, $\| x_{j}-$ $u \| \leq m+\eta$ and $\left\|x_{j}-v\right\| \leq m+\eta$ for all sufficiently large $j$. Let $p=(1 / 2)(u+v)$, which is in $C$ by the convexity of $C$. The uniform convexity in the direction $z$ implies that $\left\|x_{j}-p\right\| \leq(1-\delta(\varepsilon, z))(m+\eta)$ for all sufficiently large $j$ once we note that 


$$
\begin{gathered}
(m+\eta)^{-1}\left\|x_{j}-p\right\|=\frac{1}{2}\left\|\frac{x_{j}-u}{m+\eta}+\frac{x_{j}-v}{m+\eta}\right\|, \\
(m+\eta)^{-1}\left\|x_{j}-u\right\| \leq 1, \quad(m+\eta)^{-1}\left\|x_{j}-v\right\| \leq 1, \\
(m+\eta)^{-1}\left[\left(x_{j}-v\right)-\left(x_{j}-u\right)\right]=(m+\eta)^{-1}(u-v)=(m+\eta)^{-1} \lambda z
\end{gathered}
$$

with $(m+\eta)^{-1} \lambda \geq \varepsilon$. Hence $f(p)<m$, a contradiction. Therefore, $A\left(C,\left\{x_{j}\right\}\right)$ consists of exactly one point.

LEMMA 2.3. Let $C=Y_{k=1}^{n} C_{k}$ be a finite union of nonempty weakly compact convex subsets $C_{k}$ of a UCED Banach space $X$, and let $u_{k} \in C_{k}$ be the unique asymptotic center of a bounded sequence $\left\{x_{j}\right\}$ in $X$ with respect to $C_{k}, 1 \leq k \leq n$. Then

$$
r\left(C,\left\{x_{j}\right\}\right)=\min \left\{r\left(u_{k},\left\{x_{j}\right\}\right): 1 \leq k \leq n\right\} .
$$

Proof. Let $m=\min \left\{r\left(u_{k},\left\{x_{j}\right\}\right): k=1,2, \ldots, n\right\}$. Then for any $x \in C$, there is $i$ such that $x \in C_{i}$, and so

$$
r\left(x,\left\{x_{j}\right\}\right) \geq r\left(C_{i},\left\{x_{j}\right\}\right)=r\left(u_{i},\left\{x_{j}\right\}\right) \geq m
$$

Taking the infimum for $x$ over $C$ yields $r\left(C,\left\{x_{j}\right\}\right) \geq m$. On the other hand, choose $i \in\{1,2, \ldots, n\}$ such that $r\left(u_{i},\left\{x_{j}\right\}\right)=m$. Then,

$$
m=r\left(u_{i},\left\{x_{j}\right\}\right)=r\left(C_{i},\left\{x_{j}\right\}\right) \geq \inf \left\{r\left(x,\left\{x_{j}\right\}\right): x \in C\right\}=r\left(C,\left\{x_{j}\right\}\right)
$$

This completes the proof.

LEMMA 2.4. Under the same hypothesis as Lemma 2.3,

$$
A\left(C,\left\{x_{j}\right\}\right)=\left\{u_{i}: r\left(u_{i},\left\{x_{j}\right\}\right)=m\right\} \neq \varnothing,
$$

where

$$
m=\min \left\{r\left(u_{k},\left\{x_{j}\right\}\right): 1 \leq k \leq n\right\} .
$$

Proof. If $u_{i}$ satisfies $r\left(u_{i},\left\{x_{j}\right\}\right)=m$, then it follows from Lemma 2.3 that $r\left(u_{i},\left\{x_{j}\right\}\right)=r\left(C,\left\{x_{j}\right\}\right)$, which implies that $u_{i} \in A\left(C,\left\{x_{j}\right\}\right)$. For the other inclusion, let $v$ be any member of $A\left(C,\left\{x_{j}\right\}\right)$. Choose $C_{k}$ such that $v \in C_{k}$. Then

$$
r\left(v,\left\{x_{j}\right\}\right)=m \leq r\left(u_{k},\left\{x_{j}\right\}\right) \leq r\left(v,\left\{x_{j}\right\}\right),
$$

so $r\left(v,\left\{x_{j}\right\}\right)=m=r\left(u_{k},\left\{x_{j}\right\}\right)$. By the uniqueness of the asymptotic center, we see that $v=u_{k} \in\left\{u_{i}: r\left(u_{i},\left\{x_{j}\right\}\right)=m\right\}$.

LEMmA 2.5. Under the same hypothesis as Lemma 2.3, and suppose that $T: C \rightarrow C$ is nonexpansive. Then for any $z \in C, A\left(C,\left\{T^{j} z\right\}_{j=1}^{\infty}\right)$ is $T$-invariant. 
Proof. For each $k \in\{1,2, \ldots, n\}$, let $u_{k} \in C_{k}$ be the unique asymptotic center of $\left\{T^{j} z\right.$ with respect to the nonempty weakly compact convex subset $C_{k}, 1 \leq k \leq n$. Define $f: X \rightarrow[0, \infty)$ by $f(x)=r\left(x,\left\{T^{j} z\right\}\right)$ for $x \in X$. Then by Lemma 2.4,

$$
\varnothing \neq A\left(C,\left\{T^{j} z\right\}\right)=\left\{u_{i}: f\left(u_{i}\right)=m\right\}, \quad m=\min \left\{r\left(u_{k},\left\{T^{j} z\right\}\right): k=1,2, \ldots, n\right\} .
$$

Since $T$ is nonexpansive, for any $k \in\{1,2, \ldots, n\}$, we have

$$
f\left(T u_{k}\right)=\varlimsup_{j \rightarrow \infty}\left\|T u_{k}-T^{j} z\right\| \leq \varlimsup_{j \rightarrow \infty}\left\|u_{k}-T^{j-1} z\right\|=f\left(u_{k}\right) .
$$

Now, for any $a \in A\left(C,\left\{T^{j} z\right\}\right)$, it follows from (2.8) and (2.9) that

$$
m=f(a) \geq f(T a) \geq \inf _{x \in C} f(x)=m .
$$

Consequently, $f(T a)=m$. Appealing to (2.8) once more, we obtain that $T a \in$ $A\left(C,\left\{T^{j} z\right\}\right)$. This completes the proof.

With the aid of Lemmas 2.3, 2.4, and 2.5, we obtain one of our main results.

THEOREM 2.6. Let $C=\bigcup_{k=1}^{n} C_{k}$ be a finite union of nonempty weakly compact convex subsets $C_{k}$ of a UCED Banach space X. Suppose that $T: C \rightarrow C$ is an asymptotically regular nonexpansive mapping. Then $T$ has a fixed point in $C$.

Proof. Choose any $z \in C$. Since $C$ is $T$-invariant and $C$ is bounded, the sequence $\left\{T^{j} z\right\}_{j=1}^{\infty} \subset C$ is bounded. For any $k \in\{1,2, \ldots, n\}$, let $u_{k} \in C_{k}$ be the unique asymptotic center of $\left\{T^{j} z\right.$ with respect to the nonempty weakly compact convex subset $C_{k}$ of $X$. By Lemmas 2.4 and $2.5, A\left(C,\left\{T^{j} z\right\}\right)$ is a nonempty subset of $\left\{u_{1}, \ldots, u_{n}\right\}$ and is $T$-invariant. For any $a \in A\left(C,\left\{T^{j} z\right\}\right)$, we see via the finiteness of $A\left(C,\left\{T^{j} z\right\}\right)$ that there are distinct positive integers $p, q$ such that $T^{p} a=T^{q} a$. Assume that $q=p+r$ for some $r \in \mathbb{N}$. Define $w=T^{p} a \in A\left(C,\left\{T^{j} z\right\}\right)$. Then

$$
w=T^{p} a=T^{a} a=T^{r}\left(T^{p} a\right)=T^{r} w .
$$

This means that $w$ is a fixed point of $T^{r}$. Put $n_{k}=k r, k \in \mathbb{N}$. It follows from the asymptotic regularity of $T$ at $w$ that

$$
\|T w-w\|=\left\|T^{n_{k}+1} w-T^{n_{k}} w\right\| \longrightarrow 0 \quad \text { as } n_{k} \longrightarrow \infty .
$$

Hence $T w=w$. This completes the proof.

Since it is not known whether every $\lambda$-firmly nonexpansive mapping is asymptotic regular, the generalization of the Smarzewski fixed point theorem to $\lambda$-firmly nonexpansive mappings does not follow directly from Theorem 2.6. However, the proof of the following theorem is similar to that of Theorem 2.6. To begin, we recall the following known lemma.

LEMмA 2.7 [6, Lemma 2.2]. Suppose that $C$ is any nonempty subset of a strictly convex Banach space $X$, and that $T: C \rightarrow C$ is a $\lambda$-firmly nonexpansive mapping for some $\lambda \in(0,1)$. If $x, y$ are in $C$ so that $\|T x-T y\|=\|x-y\|$, then $T x-T y=x-y$. 
THEOREM 2.8. Let $C=\bigcup_{k=1}^{n} C_{k}$ be a finite union of nonempty weakly compact convex subsets $C_{k}$ of a UCED Banach space $X$. If $T: C \rightarrow C$ is $\lambda$-firmly nonexpansive for some $\lambda \in(0,1)$, then $T$ has a fixed point in $C$.

Proof. Choose any $z \in C$. The sequence $\left\{T^{j} z\right\}_{j=1}^{\infty}$ is bounded in $C$. So, it follows from Lemma 2.2 that for any $k \in\{1,2, \ldots, n\},\left\{T^{j} z\right\}$ has a unique asymptotic center $u_{k}$ with respect to the nonempty weakly compact convex subset $C_{k}$. By Lemmas 2.4 and 2.5, $A\left(C,\left\{T^{j} z\right\}\right)$ is a nonempty subset of $\left\{u_{1}, \ldots, u_{n}\right\}$ and is $T$-invariant. So, there is $w \in A\left(C,\left\{T^{j} z\right\}\right)$ and $\ell \in \mathbb{N}$ such that $T^{\ell} w=w$. If $\ell=1, T$ has a fixed point $w$ in $C$. Otherwise, noting that

$$
\|w-T w\|=\left\|T^{\ell} w-T^{\ell+1} w\right\| \leq\left\|T^{\ell-1} w-T^{\ell} w\right\| \leq \cdots \leq\left\|T w-T^{2} w\right\| \leq\|w-T w\|,
$$

it follows from Lemma 2.7 that

$$
w-T w=T w-T^{2} w=\cdots=T^{\ell-1} w-T^{\ell} w
$$

which implies that

$$
\begin{aligned}
w= & T^{\ell} w=T^{\ell-1} w-x \\
= & \left(T^{\ell-2} w-x\right)-x \\
= & T^{\ell-2} w-2 x \\
& \vdots \\
= & w-\ell x, \quad \text { where } x=w-T w .
\end{aligned}
$$

Consequently, $\ell x=0$ and hence $x=0$, that is, $T w=w$. This completes the proof.

For the case that $k=1$, we have the following corollary.

COROLLARY 2.9. Let $C$ be a nonempty weakly compact convex subset of a UCED Banach space $X$. Suppose $T: C \rightarrow C$ is a $\lambda$-firmly nonexpansive mapping for some $\lambda \in(0,1)$. Then $T$ has a fixed point in $C$.

The following conclusion is immediate from Theorem 2.8 and the fact that every uniformly convex Banach space is a UCED Banach space.

COROLlary 2.10 [9]. Suppose that $C=\bigcup_{k=1}^{n} C_{k}$ is a finite union of nonempty weakly compact convex subsets $C_{k}$ of a uniformly convex Banach space $X$ and that $T: C \rightarrow C$ is a $\lambda$-firmly nonexpansive mapping for some $\lambda \in(0,1)$. Then $T$ has a fixed point in $C$.

3. A common fixed point theorem for strongly nonexpansive mappings. By $[3$, Proposition 1.2], it is easy to see that every strongly nonexpansive mapping $T: C \rightarrow C$ on a nonempty bounded closed subset $C$ of a Banach space $X$ is asymptotically regular. With this observation, the result of Theorem 2.6 can be strengthened.

THEOREM 3.1. Let $X$ be a UCED Banach space, and let $C=\bigcup_{k=1}^{n} C_{k}$ be a finite union of nonempty weakly compact convex subsets $C_{k}$ of $X$. Suppose that $T: C \rightarrow C$ 
is a strongly nonexpansive mapping. Then for any $z$ in $C, A\left(C,\left\{T^{j} z\right\}_{j=1}^{\infty}\right) \neq \varnothing$ and $A\left(C,\left\{T^{j} z\right\}_{j=1}^{\infty}\right) \subseteq F(T)$.

Proof. For each $k \in\{1,2, \ldots, n\}$, let $u_{k} \in C_{k}$ be the unique asymptotic center of $\left\{T^{j} z\right\}$ with respect to $C_{k}$. By Lemmas 2.4 and 2.5 , we see that $A\left(C,\left\{T^{j} z\right\}\right)$ is a finite nonempty subset of $\left\{u_{1}, \ldots, u_{n}\right\}$ and is $T$-invariant. Moreover, from the proof of Theorem 2.6, we see that for any $a \in A\left(C,\left\{T^{j} z\right\}\right)$ there is $\ell \in \mathbb{N}$ such that $T^{\ell} a$ is a fixed point of $T$. Let $\eta=T^{\ell-1} a$ and $w=T^{\ell} a$. Then $T \eta=w$ and $T w=w$. Let $m$ be the asymptotic radius of $\left\{T^{j} z\right\}$ with respect to $C$. Then

$$
\varlimsup_{j \rightarrow \infty}\left\|\eta-T^{j} z\right\|=m=\varlimsup_{j \rightarrow \infty}\left\|w-T^{j} z\right\|=\lim _{j \rightarrow \infty}\left\|w-T^{j} z\right\|,
$$

where the last equality follows from the monotonicity of the sequence $\left\{\left\|w-T^{j} z\right\|\right\}_{j=1}^{\infty}$. Now we claim that $\lim _{j \rightarrow \infty}\left\|\eta-T^{j} z\right\|=m$, also. In fact, by the nonexpansiveness of $T$ we see that

$$
\varliminf_{j \rightarrow \infty}\left\|T \eta-T^{j+1} z\right\| \leq \varliminf_{j \rightarrow \infty}\left\|\eta-T^{j} z\right\|,
$$

and hence

$$
\begin{aligned}
m & =\varlimsup_{j \rightarrow \infty}\left\|\eta-T^{j} z\right\| \geq \varliminf_{j \rightarrow \infty}\left\|\eta-T^{j} z\right\| \geq \varliminf_{j \rightarrow \infty}\left\|T \eta-T^{j+1} z\right\| \\
& =\varliminf_{j \rightarrow \infty}\left\|w-T^{j+1} z\right\|=m .
\end{aligned}
$$

Therefore, we have

$$
\begin{gathered}
\left\|w-T^{j} z\right\|-\left\|T w-T^{j+1} z\right\| \longrightarrow 0, \\
\left\|\eta-T^{j} z\right\|-\left\|T \eta-T^{j+1} z\right\| \longrightarrow 0 \text { as } j \longrightarrow \infty .
\end{gathered}
$$

It then follows from the strong nonexpansiveness of $T$ that

$$
\begin{gathered}
\left(w-T^{j} z\right)-\left(T w-T^{j+1} z\right) \longrightarrow 0, \\
\left(\eta-T^{j} z\right)-\left(T \eta-T^{j+1} z\right) \longrightarrow 0 \text { as } j \longrightarrow \infty .
\end{gathered}
$$

Since

$$
\begin{aligned}
\|\eta-T \eta\| & =\|(\eta-w)-(T \eta-T w)\| \\
& \leq\left\|\left(\eta-T^{j} z\right)-\left(T \eta-T^{j+1} z\right)\right\|+\left\|\left(w-T^{j} z\right)-\left(T w-T^{j+1} z\right)\right\|,
\end{aligned}
$$

we conclude that $\eta=T \eta$. Thus, we have shown that $T^{\ell-1} a$ is also a fixed point of $T$ whenever $T^{\ell} a$ is a fixed point of $T$. Repeating this argument, we finally obtain that $a$ is a fixed point of $T$. This completes the proof.

A family $\left\{T_{i}\right\}_{i \in I}$ of self-mappings on a metric space $(X, d)$ is said to be weakly commutative if $d\left(T_{i} T_{j} x, T_{j} T_{i} x\right) \leq d\left(T_{j} x, T_{i} x\right)$ for any $i, j \in I$ and for any $x$ in $X$. $\left\{T_{i}\right\}_{i \in I}$ is said to be compatible if $\lim _{n \rightarrow \infty} d\left(T_{i} T_{j} x_{n}, T_{j} T_{i} x_{n}\right)=0$ whenever $\left\{x_{n}\right\}$ is a sequence in $X$ such that for some $t \in X, \lim _{n \rightarrow \infty} T_{i}\left(x_{n}\right)=\lim _{n \rightarrow \infty} T_{j}\left(x_{n}\right)=t$ for all $i, j \in I$. Obviously, a weakly commutative family is compatible but not conversely ([7]).

Just as the proof of [7, Proposition 2.2], we have the following lemma. 
LEMMA 3.2. Suppose that $\left\{T_{i}\right\}_{i \in I}$ is a compatible family of self-mappings on a metric space $(X, d)$. If $z \in X$ is such that $T_{i} z=T_{j} z$ for all $i, j \in I$, then $T_{i} T_{j} z=T_{j} T_{i} z$ for all $i, j \in I$.

THEOREM 3.3. Let $C=\bigcup_{k=1}^{n} C_{k}$ be a finite union of nonempty weakly compact convex subsets $C_{k}$ of a UCED Banach space $X$, and let $\left\{T_{i}\right\}_{i \in I}$ be any compatible family of strongly nonexpansive self-mappings on $C$. Suppose that the graphs of $T_{i}, i \in I$, have a nonempty intersection, then $T_{i}, i \in I$, have a common fixed point in $C$.

Proof. By assumption, there is $z \in C$ such that $T_{i} z=T_{j} z$ for all $i, j \in I$. Then in view of Lemma 3.2, we have $T_{i} T_{j} z=T_{j} T_{i} z$ for all $i, j \in I$. Consequently,

$$
T_{i}^{2} z=T_{i}\left(T_{j} z\right)=T_{j}\left(T_{i} z\right)=T_{j}^{2} z
$$

for all $i, j \in I$. By induction, we obtain that $T_{i}^{k} z=T_{j}^{k} z$ for any $k \in \mathbb{N}$ and for all $i, j \in I$. Then from the proof of Theorem 3.1, we see that $A\left(C,\left\{T_{i}^{n} z\right\}_{n=1}^{\infty}\right) \neq \varnothing$ and any point $w$ in $A\left(C,\left\{T_{i}^{n} z\right\}_{n=1}^{\infty}\right)$ is a common fixed point of $T_{j}, j \in I$. This completes the proof.

\section{REFERENCES}

[1] J. B. Baillon, R. E. Bruck, and S. Reich, On the asymptotic behavior of nonexpansive mappings and semigroups in Banach spaces, Houston J. Math. 4 (1978), no. 1, 1-9.

[2] F. E. Browder, Nonexpansive nonlinear operators in a Banach space, Proc. Nat. Acad. Sci. U.S.A. 54 (1965), 1041-1044.

[3] R. E. Bruck and S. Reich, Nonexpansive projections and resolvents of accretive operators in Banach spaces, Houston J. Math. 3 (1977), no. 4, 459-470.

[4] K. Goebel and S. Reich, Uniform Convexity, Hyperbolic Geometry, and Nonexpansive Mappings, Monographs and Textbooks in Pure and Applied Mathematics, vol. 83, Marcel Dekker, New York, 1984.

[5] D. Göhde, Zum Prinzip der kontraktiven Abbildung, Math. Nachr. 30 (1965), 251-258 (German).

[6] Y. M. Hong and Y. Y. Huang, On X-firmly nonexpansive mappings in nonconvex sets, Bull. Inst. Math. Acad. Sinica 21 (1993), no. 1, 35-42.

[7] G. Jungck, Compatible mappings and common fixed points, Int. J. Math. Math. Sci. 9 (1986), no. 4, 771-779.

[8] W. A. Kirk, A fixed point theorem for mappings which do not increase distances, Amer. Math. Monthly 72 (1965), 1004-1006.

[9] R. Smarzewski, On firmly nonexpansive mappings, Proc. Amer. Math. Soc. 113 (1991), no. 3, 723-725.

Wei-ShiH DU: DePARTMENT OF MATHEMATICS, NATIONAL ChANGHUA UNIVERSity OF EDUCATION, Changhua 500, TAIWAN, R.O.C.

E-mail address: dws58043@ms38. hinet.net

Young-Ye Huang: Department of Mathematics, National Cheng Kung University, TAINAN 701, TAIWAN, R.O.C.

E-mail address: yue@math.ncku.edu. tw

Chi-Lin Yen: Department of Mathematics And SCience Education, National Hsinchu TEACHeR'S COllege, HSINCHu 300, TAiwAN, R.O.C.

E-mail address: presdt@mai 1. nhctc.edu.tw 


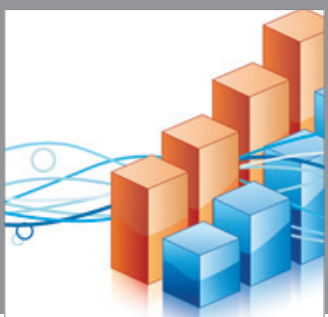

Advances in

Operations Research

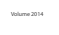

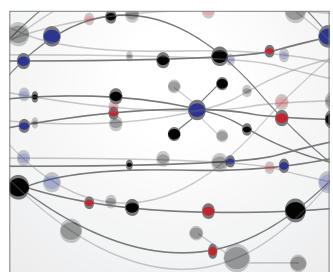

\section{The Scientific} World Journal
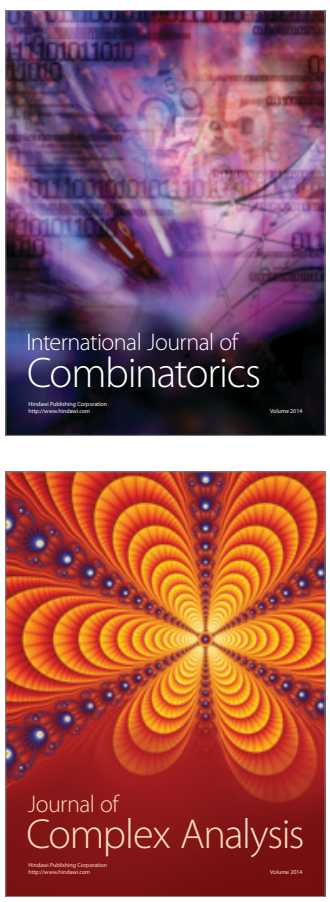

International Journal of

Mathematics and

Mathematical

Sciences
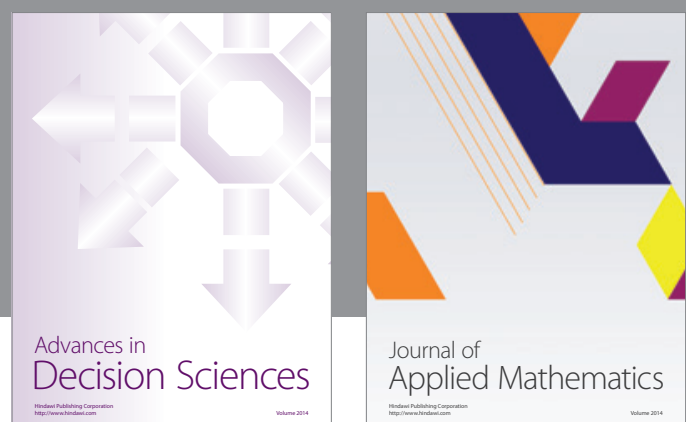

Journal of

Applied Mathematics
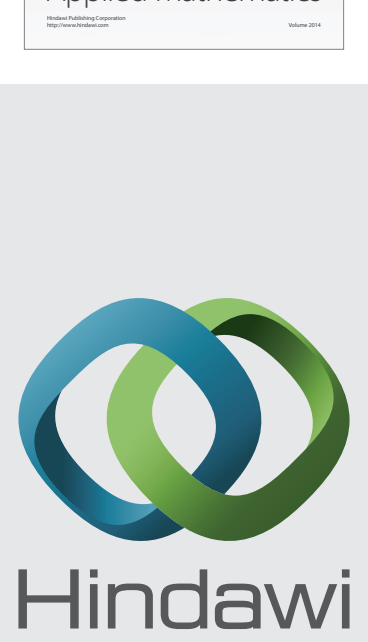

Submit your manuscripts at http://www.hindawi.com
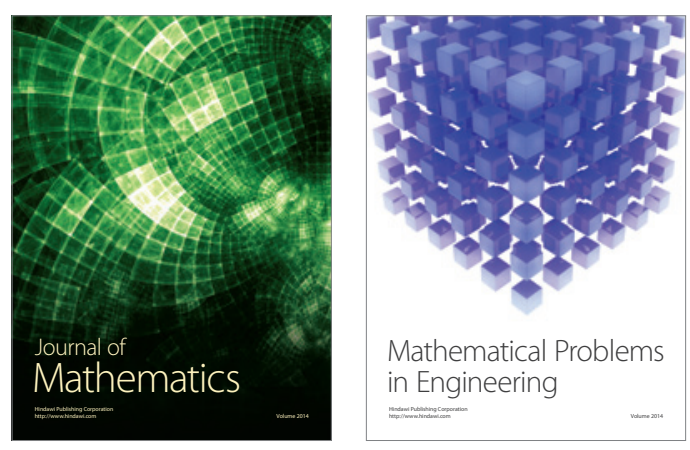

Mathematical Problems in Engineering
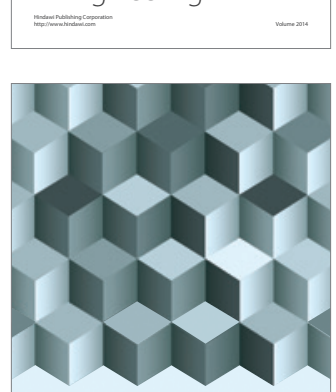

Journal of

Function Spaces
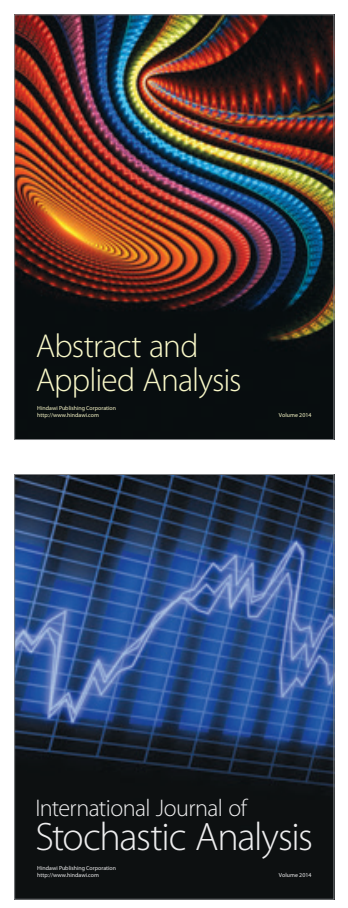

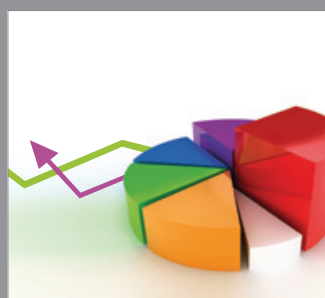

ournal of

Probability and Statistics

Promensencen
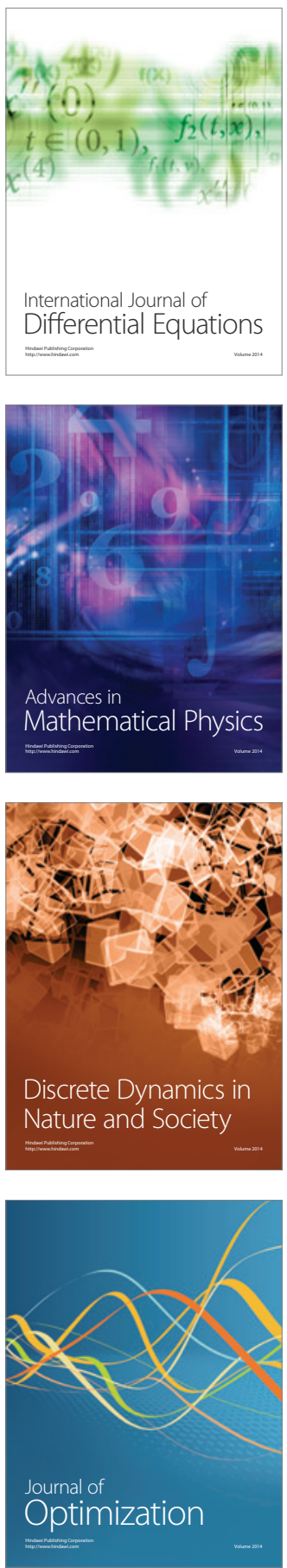